\title{
Functional promiscuity in a mammalian chemosensory system: extensive expression of vomeronasal receptors in the main olfactory epithelium of mouse lemurs
}

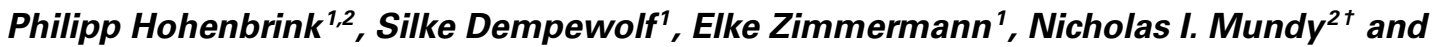 \\ Ute Radespiel ${ }^{1 * t}$
}

${ }^{1}$ Institute of Zoology, University of Veterinary Medicine Hannover, Hannover, Germany

${ }^{2}$ Department of Zoology, University of Cambridge, Cambridge, UK

\author{
Edited by: \\ Pablo Chamero, University of \\ Saarland, Germany \\ Reviewed by: \\ Dominique G. Giorgi, Centre \\ National de la Recherche \\ Scientifique, France \\ Tim D. Smith, Slippery Rock \\ University, USA

\section{*Correspondence:} \\ Ute Radespiel, Institute of Zoology, \\ University of Veterinary Medicine \\ Hannover, Buenteweg 17, 30559 \\ Hannover, Germany \\ e-mail: ute.radespiel@ \\ tiho-hannover.de \\ ${ }^{\dagger}$ These authors have contributed \\ equally to this work.
}

The vomeronasal organ (VNO) is functional in most terrestrial mammals, though progressively reduced in the primate lineage, and is used for intraspecific communication and predator recognition. Vomeronasal receptor (VR) genes comprise two families of chemosensory genes (V1R and $V 2 R$ ) that have been considered to be specific for the VNO. However, recently a large number of VRs were reported to be expressed in the main olfactory epithelium (MOE) of mice, but there is little knowledge of the expression of these genes outside of rodents. To explore the function of VR genes in mammalian evolution, we analyzed and compared the expression of $64 V 1 R$ and $2 V 2 R$ genes in the $\mathrm{VNO}$ and the MOE of the gray mouse lemur (Microcebus murinus), the primate with the largest known VR repertoire. We furthermore compared expression patterns in adults of both sexes and seasons, and in an infant. A large proportion (83-97\%) of the VR loci was expressed in the VNO of all individuals. The repertoire in the infant was as rich as in adults, indicating reliance on olfactory communication from early postnatal development onwards. In concordance with mice, we also detected extensive expression of VRs in the MOE, with proportions of expressed loci in individuals ranging from 29 to $45 \%$. TRPC2, which encodes a channel protein crucial for signal transduction via VRs, was co-expressed in the MOE in all individuals indicating likely functionality of expressed VR genes in the MOE. In summary, the large VR repertoire in mouse lemurs seems to be highly functional. Given the differences in the neural pathways of MOE and VNO signals, which project to higher cortical brain centers or the limbic system, respectively, this raises the intriguing possibility that the evolution of MOE-expression of VRs enabled mouse lemurs to adaptively diversify the processing of VR-encoded olfactory information.

Keywords: MOE, VNO, V1R, V2R, TRPC2, olfaction, primate, Microcebus

\section{INTRODUCTION}

Most terrestrial mammals use two olfactory systems, the main olfactory system based on the main olfactory epithelium (MOE) and the accessory olfactory system based on the vomeronasal organ (VNO). The MOE has traditionally been considered to detect small odorants and a few pheromones (Restrepo et al., 2004), whereas the VNO is specialized for the detection of pheromones, signature mixtures and kairomones (e.g., predator cues) (Keverne, 1999; Isogai et al., 2011) and is therefore essential for intraspecific communication and predator avoidance. Two types of vomeronasal receptors (VRs) are described which have been thought to be primarily expressed in the VNO based on studies in rodents: vomeronasal 1 receptors (V1Rs, Dulac and Axel, 1995) and vomeronasal 2 receptors (V2Rs, Herrada and Dulac, 1997; Matsunami and Buck, 1997; Ryba and Tirindelli,

Abbreviations: MOE, Main olfactory epithelium; TRPC2, Transient receptor potential channel type C2; VNO, Vomeronasal organ; V1R, Vomeronasal receptor type 1; V2R, Vomeronasal receptor type 2; VR, Vomeronasal receptor.
1997). The two receptor types seem to be specialized for ligands of different size: V1Rs bind smaller molecules (LeindersZufall et al., 2000), whereas V2Rs bind larger peptides (like Major Histocompatibility Complex: Leinders-Zufall et al., 2004; Endocrine gland-Secreting Peptide 1: Kimoto et al., 2005; and Major Urinary Proteins: Chamero et al., 2007). The broader pattern of expression is yet unclear and a few cells of the MOE in mice and goats express single V1Rs (Wakabayashi et al., 2002; Karunadasa et al., 2006; Ohara et al., 2009). However, a recent study using nano Cap Analysis of Gene Expression revealed the expression of a large proportion of VRs in the mouse MOE (112 of 191 tested V1Rs and 96 of 123 V2Rs; Pascarella et al., 2014). Both types of VRs use the cation channel TRPC2 (Transient Receptor Potential channel type C2) in the signal transduction pathway (Liman et al., 1999). Although one study did not find TRPC2 expression outside of the mouse VNO (Zhang et al., 2010), another study reported a very faint signal for TRPC2 in the MOE on Northern blots and a faint signal in a small population of MOE 
cells by in situ hybridization (Liman et al., 1999). Furthermore, tag clusters associated to TRPC2 were found in MOE tissue of mice (Pascarella et al., 2014).

In primates it was observed that the size of the VNO correlates with its functionality: it is well developed and functional in strepsirrhine primates (lemurs and lorisoids), smaller but still functional in tarsiers and most New World monkeys and vestigial or absent in catarrhine primates (Old World monkeys, apes and humans) (Martin, 1990; Smith et al., 2011; Garrett et al., 2013). V1R repertoires in strepsirrhine primates (78-214 estimated genes) are as large as in rodents (89-239 estimated genes, Young et al., 2010), whereas only 2 intact $V 2 R$ genes have been described in strepsirrhines (Hohenbrink et al., 2013) in contrast to about 100 intact genes in rodents (Young and Trask, 2007). Catarrhine primates lack functional V2Rs and the few intact V1Rs are not considered to be functional in the VNO, since TRPC2 is a pseudogene in catarrhines including humans (Liman and Innan, 2003; Zhang and Webb, 2003; Young and Trask, 2007; Young et al., 2010).

Strepsirrhine primates are ideal to study the vomeronasal system in non-model species as they heavily rely on olfactory communication (Jolly, 1966; Perret, 1995; Buesching et al., 1998; Braune et al., 2005; DelBarco-Trillo et al., 2011) and olfactory predator recognition has been described in mouse lemurs (Sündermann et al., 2008; Kappel et al., 2011). Although large genomic repertoires of vomeronasal receptors (VRs) have been identified in strepsirrhine primates (Young et al., 2010; Yoder et al., 2014), little is known about the expression patterns of the genes. Thus it is currently unclear whether the pattern of expression found in mice is representative of other mammals, which has important consequences for understanding the functional role of VRs.

To further our understanding of the role of VNO and MOE in the olfactory system of mammals and to shed light on the evolution of this sensory modality in primates, we analyze the expression patterns of VRs and TRPC2 in gray mouse lemurs (Microcebus murinus). Among strepsirrhine primates mouse lemurs are an ideal model system as large parts of their genome is available and the organization of their $V 1 R$ and $V 2 R$ repertoires has already been analyzed (Young et al., 2010; Hohenbrink et al., 2012, 2013). Notably, they possess one of the largest predicted $V 1 R$ repertoire of any mammal, comprising at least nine monophyletic gene clusters that have mostly evolved under positive selection (Hohenbrink et al., 2012). For this study we analyzed expression of a large proportion of $V 1 R$ and $V 2 R$ loci in the $\mathrm{VNO}$ and MOE of both sexes and both seasons (reproductive and non-reproductive season). We also studied a young infant to identify expression patterns at a very early postnatal developmental age. We ask whether a high proportion of the VR repertoire is expressed in the VNO, and if this varies with age, sex, or season. We also ask whether VR expression in the MOE is as widespread as recently shown in mice.

\section{MATERIALS AND METHODS TISSUE COLLECTION}

Complete VNOs and MOE tissues were collected from freshly deceased gray mouse lemurs that were euthanized for veterinary reasons or died naturally. No animal was sacrificed for the purpose of this study. All individuals were housed in the breeding colony of the Institute of Zoology of the University of Veterinary Medicine in Hannover under seasonal light regimes (see Wrogemann and Zimmermann, 2001 for details). The international and national guidelines for the care and housing of animals were followed namely the NRC Guide for the Care and Use of Laboratory Animals, the European Directive 2010/63/EU on the protection of animals used for scientific purposes, and the German Animal Welfare Act (licensed by the Bezirksregierung Hannover, reference number AZ 33.9-42502-05-10A080, and by Ordnungsamt, Gewerbe- und Veterinärabteilung, Landeshauptstadt Hannover, AZ 42500/1H). Animals used in this study died between March 2012 and April 2013 and were not visually impaired (Dubicanac, personal communication). We selected four different adults to detect seasonal and sex differences (see Table 1 for details). We also tested one female infant and removed tissue from the maxilloturbinals of one adult as a negative control. Maxilloturbinal tissue is nonsensory (no olfactory mucosa) but nasal tissue in close proximity to the vomeronasal organ (Smith and Rossie, 2008). If maxilloturbinal tissue was not contaminated with VNO cells during its removal, we assume that MOE tissue was also not contaminated with VNO cells and potential expression patterns of VRs in MOE tissue shown in this study relate to actual expression in the MOE. We were not able to obtain a MOE sample for the female that died during the non-reproductive season due to technical problems during the dissection. All tissue samples were stored in RNAlater (Qiagen) at $-80^{\circ} \mathrm{C}$ immediately after removal and RNA was extracted up to one year after storage using the RNeasy Micro Kit (Qiagen). The 260/280 nm absorbance ratios of all extracted RNA samples were close to 2.0 indicating high RNA purity (instead of 1.8 for DNA). Transcription into cDNA was performed with the Quantitect Reverse Transcription Kit (Qiagen) and N6 primer, according to manufacturer's instructions. The extraction and transcription kits both contain steps by the manufacturer to eliminate genomic DNA by DNase treatment. The successful extraction of RNA and synthesis of cDNA was confirmed by amplifying an intron-spanning segment of ACTB (beta-actin; ACTB-Exon-4-fw CTG TGC TGT CCC TGT ACG C, ACTB-Exon-6-rv AGT CCG CCT AGA AGC ATT TG), for which intronless cDNA was shorter on an agarose gel than

Table 1 | Tissue samples with information about age and sex of animal and season during the time of death.

\begin{tabular}{lcccll}
\hline Animal & Sex & Season & Death & Age & Organ \\
\hline Zambo & M & R & $2012-04-26$ & 11.9 years & VNO, MOE \\
Uma & F & R & $2013-03-14$ & 7.9 years & VNO, MOE \\
Vincent & M & NR & $2012-10-09$ & 8.3 years & VNO, MOE \\
Tanja & F & NR & $2012-09-20$ & 6.3 years & VNO \\
Infant & F & - & $2013-04-25$ & 10 days & VNO, MOE \\
Ursina & F & R & $2012-03-13$ & 8.9 years & MT \\
\hline
\end{tabular}

$M$, male; F, female; $R$, Reproductive season; NR, Non-reproductive season; MOE, Main olfactory epithelium; VNO, Vomeronasal organ; MT, Maxilloturbinal. Light conditions during housing were adjusted to the Northern hemisphere. 
genomic control DNA. Amplification and sequencing of an intron-spanning fragment of TRPC2 was used to confirm its expression. Primers for TRPC2 were TRPC2-A2 (TGA GCC AGG ACT ATG GCT TT) and TRPC2-B (Talarico, 2006: CAG GTT CCC ACA CCA GAT G), which bind to exon 3 and 4, respectively (PCR conditions below). No long intron-containing bands were found on the agarose gel after amplification of TRPC2 and ACTB and together with the $260 / 280$ absorption ratio and the two steps of genomic DNA elimination during RNA extraction and reverse transcription we exclude any contamination of our samples with genomic DNA.

\section{CONFIRMATION OF TRANSCRIBED LOCI}

We developed locus-specific PCR assays to assess the expression of VRs as currently described. From the 107 previously published $V 1 R$ sequences of the gray mouse lemur (Zhang et al., 2010) we excluded 29 loci, because they had no full length sequence (VN1R Mmur073) or did not fulfill the following criteria: (1) locus has at least $1 \%$ nucleotide differences to other loci (or else one of the two highly similar loci was excluded), (2) primers had not been rejected by the online software Primer3Plus (Untergasser et al., 2007) due to low/high annealing temperature or self assembly using default settings, and (3) the primer pair amplifies at least 500 bp of the target locus. Consequently, we designed locusspecific primer pairs for each of the remaining $78 \mathrm{~V} 1 \mathrm{R}$ loci. The lowest sequence divergence between two loci for which locusspecific primer pairs were designed was $\sim 3 \%$ (=28 bp differences) and amplicons were at least 540 bp long (Table 2). $V 1 R$ loci are named VN1R Mmur000 to VN1R Mmur103 (882-1008 bp, Hohenbrink et al., 2012); V2R loci are named VN2R1 (2739 bp) and VN2R2 (2418 bp) (Hohenbrink et al., 2013).

The specificity of the newly designed $V 1 R$ primer pairs was tested by amplifying and sequencing one cDNA sample (VNO tissue, male, reproductive season) and genomic DNA as a positive control. Sequencing genomic DNA enabled confirmation of specificity of each primer pair even if the locus is not expressed in the VNO sample. $V 2 R$ primers were already validated (Hohenbrink et al., 2013). For the positive control genomic DNA was extracted from ear tissue using a DNeasy Tissue Kit (Qiagen) and a REPLI-g WGA kit (Qiagen). All VR fragments were amplified with MyTaq DNA polymerase (Bioline; $25 \mu \mathrm{l}$ total volume containing $5 \mu \mathrm{l}$ MyTaq Reaction Buffer, $1 \mu \mathrm{l}$ of each primer $[10 \mu \mathrm{M}$ stock concentration], $0.1 \mu \mathrm{l}$ Taq DNA polymerase [5 U/ $\mu \mathrm{l}]$ and $1 \mu \mathrm{l}$ of DNA) with the following PCR conditions: $94^{\circ} \mathrm{C}$ for $2 \mathrm{~min}, 40$ times $\left(94^{\circ} \mathrm{C}\right.$ for $30 \mathrm{~s}, 60^{\circ} \mathrm{C}$ for $45 \mathrm{~s}, 72^{\circ} \mathrm{C}$ for $90 \mathrm{~s}), 72^{\circ} \mathrm{C}$ for $5 \mathrm{~min}$. PCR products were sequenced on both strands using BigDye Terminator 3.1 (Applied Biosystems) under standard conditions and run on an Applied Biosystems 3500 capillary sequencing machine. Consensus sequences of single genes were built with SeqMan 5.05 (DNASTAR Inc., Madison, WI, USA). Sequences were aligned and analyzed using MEGA 5 (Tamura et al., 2011). The alignment of the sequenced fragments with the targeted loci showed that 64 of the 78 primer pairs were truly locus-specific. These $V 1 R$ primer pairs (Table 2) and the $V 2 R$ primers were used in subsequent PCRs under the same conditions with all tissue samples and run on $1 \%$ agarose gel. The presence and absence of bands was used to confirm or exclude the expression of loci in all tissue samples. All negative PCRs were repeated once to counteract PCR stochasticity and results are presented cumulatively. This method was preferred over next generation sequencing (RNA-Seq) because of the potential difficulty of correctly assembling RNA-Seq data for the large $V 1 R$ gene family, with many closely related sequences.

We were able to design primers for loci of each monophyletic $V 1 R$ cluster known from gray mouse lemurs (Hohenbrink et al., 2012). Four clusters were covered $100 \%$ (cluster II, IV, VI, and VII), whereas clusters III (75\%) and V (71\%) showed high coverage. However, for cluster VIII only one locus (20\%) could be sequenced, because the other four loci of the cluster were highly similar and designed primers were not locus-specific. Cluster I (35\%; also known as V1Rstrep, Yoder et al., 2014) and IX (50\%) are the two largest clusters in mouse lemurs and seemed to have evolved by rapid gene duplication. Cluster I was particularly difficult for primer design because of low nucleotide divergence: seven of nine loci that were excluded because of divergence below $1 \%$ belonged to this cluster.

\section{RESULTS}

TRPC2 was expressed in all VNO and MOE tissue samples in the gray mouse lemur (Figure 1A). There was no amplification of TRPC2 from the negative control of maxilloturbinal tissue, but all samples were positive for $A C T B$ (not shown), indicating successful RNA extraction and cDNA synthesis. Each of the $64 \mathrm{~V} 1 \mathrm{R}$ and the $2 V 2 R$ loci were expressed in at least one tissue sample (three examples shown in Figures 1B-D). The specific expression patterns of VR loci in VNO and MOE tissues are shown in Table 3. The sample of maxilloturbinal tissue was negative for VR loci.

The proportion of expressed V1R loci ranged from 83 to $97 \%$ in the VNO and $28-45 \%$ in the MOE samples. The number of expressed genes was significantly higher in the VNO than in the MOE (observed vs. expected: $\chi^{2}>9.66, d f=1, p<0.002$ in all four pairwise comparisons). We found no global differences in the number of expressed V1Rs between the two sexes or the two seasons neither in the VNO nor in the MOE, but one locus (VN1R Mmur074) was exclusively expressed in females. There were also no large differences between the adult individuals and the infant. Nevertheless, three loci (VN1R Mmur021, 036, and 045) were expressed in the VNO samples of all tested adults but were absent in the VNO sample of the infant. Conversely, VN1R Mmur053 was absent in the VNO tissue of all tested adults but was expressed in the infant.

At least one locus of each of the nine known monophyletic $V 1 R$ clusters was expressed in each of the five VNO tissue samples. Four loci (VN1R Mmur004, 041, 044, and 059) were expressed in all nine tissue samples, whereas $25 \mathrm{~V} 1 \mathrm{R}$ loci (39\%) were exclusively expressed in the VNO. Fourteen of these $V 1 R$ loci were expressed in all five tested VNO samples. In total, $48 \mathrm{~V} 1 \mathrm{R}$ loci (75\%) were expressed in all five VNO tissue samples meaning that variation in expression patterns in the VNO was only found in $25 \%$ of the loci. More variation existed in the MOE samples. With the exception of three loci (VN1R Mmur030, 053, and 076) every locus that was expressed in the MOE was also expressed in the 
Table 2 | List of locus-specific primer pairs for V1R loci with expected PCR product length.

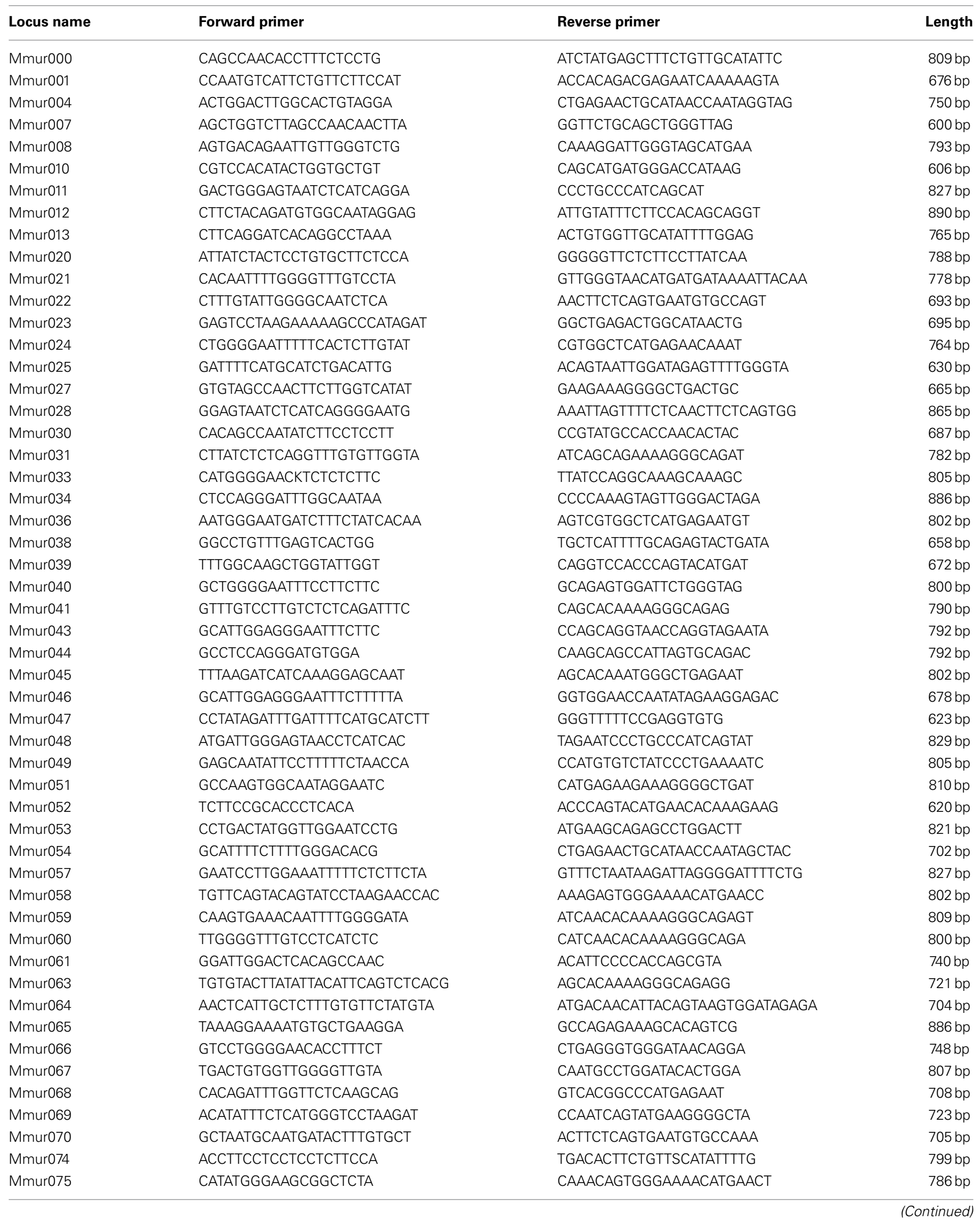


Table 2 | Continued

\begin{tabular}{lll}
\hline Locus name & Forward primer & Reverse primer \\
\hline Mmur076 & GGCTGCCTTAGATTTGTCTACAGT & AGATACAAAGGTGCTCACCAGA \\
Mmur077 & GATTGGGGTCGGGACTCTA & AGTAAGCATGGAACTCAGCACA \\
Mmur078 & TAAATTGGGCATCACTTTTCTA & GGCATCACTGACAATGAACAG \\
Mmur079 & TGCTCACCATGGTGTTTTC & ACTGTGGCATAGGCACTGA \\
Mmur082 & GGGGCATTATCTTTCTTATTCAGT & 813 bp \\
Mmur085 & TTATCTTTGTCATTCAGACTGGTGT & TAGCCCAGAGAACATACTTGGA \\
Mmur086 & ACAGATTTGGTTCTCAAGCACA & CCTAGTCCAGCAGGCAAAGT \\
Mmur087 & GAGAAGTGGCAATAGGAATGATCTA & CTTCCACAGCAGGCAGAA \\
Mmur088 & TTATCTTTGTCATTCAGACTGGTGT & GCATCGTGTAGCTACAGAGTT \\
Mmur094 & TCATTCAGACTAGTGTTGGATCTC & GACAGAGATGCCCCTCAGAA \\
Mmur101 & TGGAAGCTTTCCTGGATGG & ATGTCGGGAAGCCCAAA \\
Mmur103 & TTTTATCACTGCACAGAGACTGAATA & TGGGTTCTGCCGCTGT \\
\hline
\end{tabular}

${ }^{a}$ Mmur085 and 088 share the same forward primer (but reverse primer is specific for each locus).
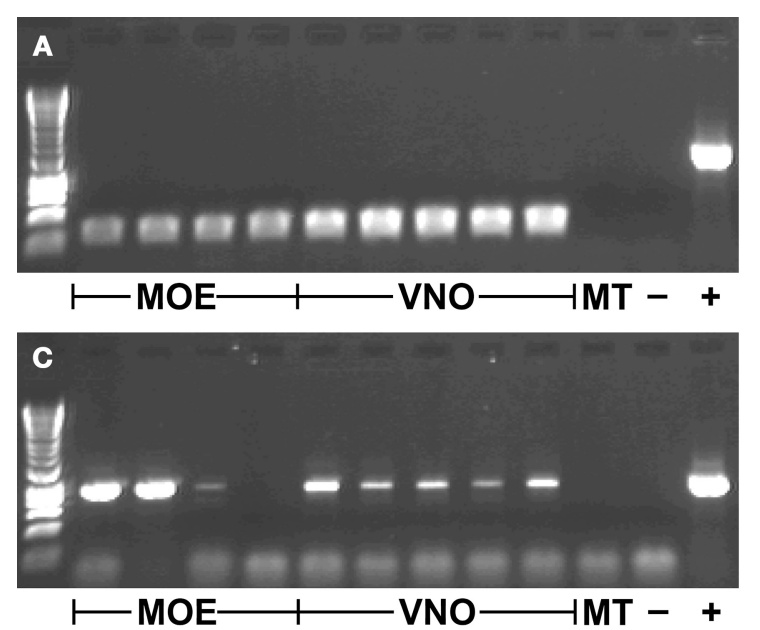

FIGURE 1 | Gene expression in different tissue samples. (A) TRPC2 ( 240 bp product); (B) VN1R Mmur078 ( 860 bp product); (C) VN1R Mmur028 ( 920 bp product); (D) VN1R Mmur034 ( 930 bp product); first

corresponding VNO sample of the same individual. The two $V 2 R$ loci were expressed in the VNO of all individuals and the MOE of both females (including the infant) were positive for VN2R1.

\section{DISCUSSION}

We have presented the detailed expression patterns of vomeronasal receptors in a primate for the first time. We were able to demonstrate the expression patterns for 64 of 107 $V 1 R$ loci and both known V2Rs. As expected, the vast majority of the tested V1Rs and both V2Rs were expressed in the VNO. However, unexpectedly, a substantial number of VRs (39 V1Rs and VN2R2) were also expressed in the MOE, which, given with TRPC2 expression in that organ, suggests that these VRs were likely functional. These results reveal a novel organization of the chemosensory system in primates and indicate greater functional overlap between the VNO and MOE than previously recognized.
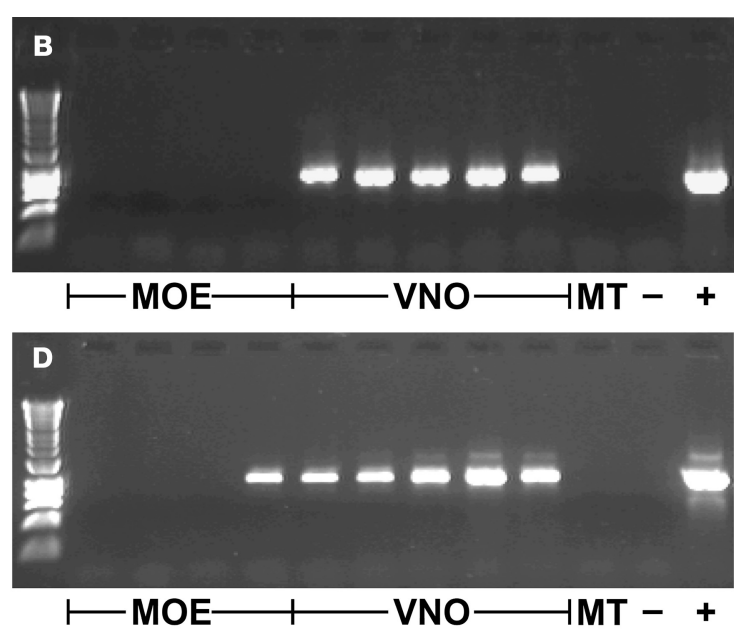

row contains HyperLadder $1 \mathrm{~kb}$ (Bioline); MOE, Main olfactory epithelium; VNO, Vomeronasal organ; MT, Maxilloturbinal; -, Blank negative control; +, Positive control of genomic DNA ( 1500 bp product for TRPC2). 


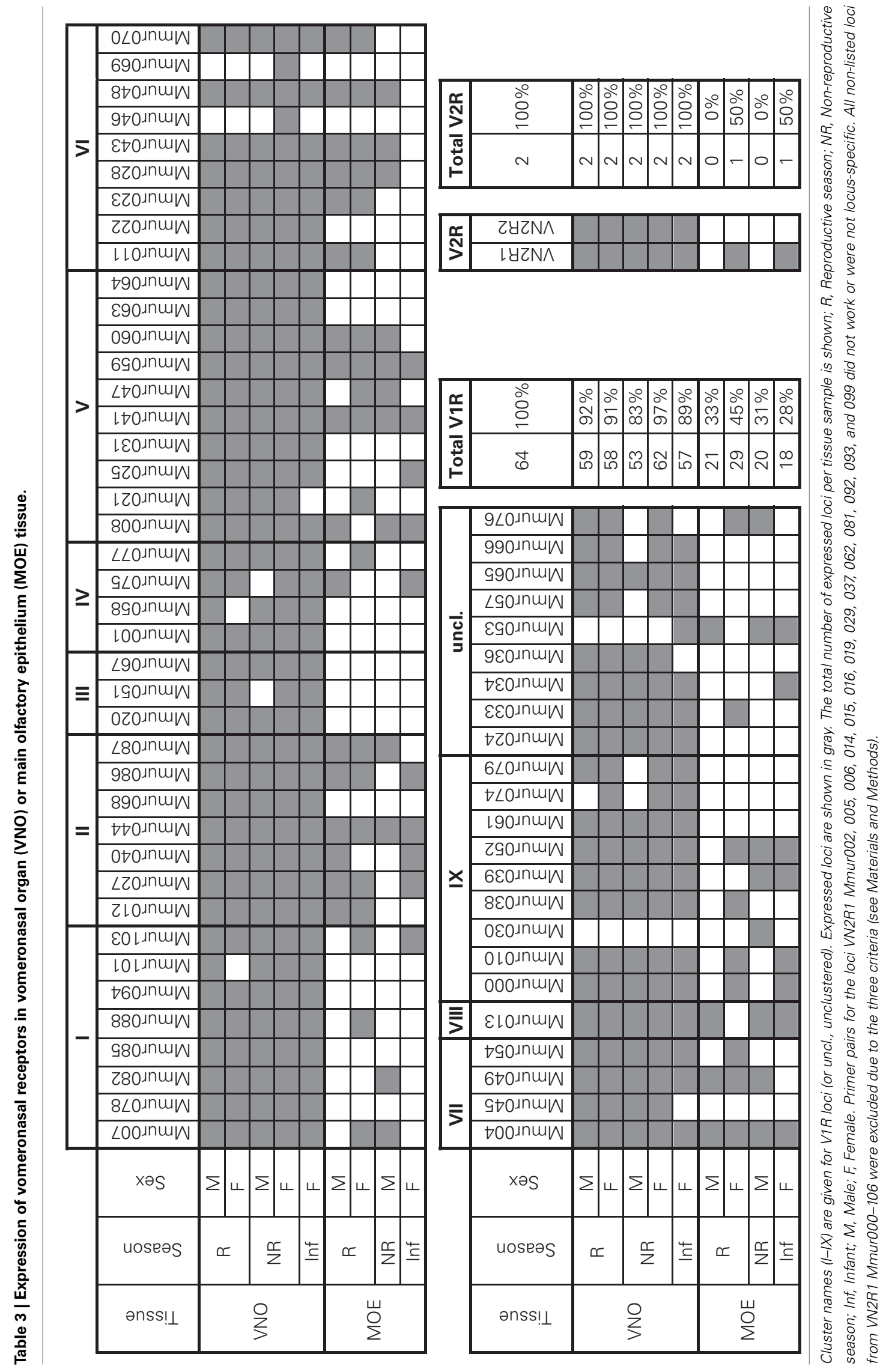


at a lower age with constant increase of expression postnatally until the age of 3-4 months (already adult) with a slight decrease at a later age. This suggests that VRs unlike olfactory receptors need to be highly expressed from early life onwards. This is in concordance with our results in mouse lemurs where the infant showed a high proportion of expressed VRs similar to adult individuals (adulthood in mouse lemurs reached after less than 1 year, Glatston, 1979), although no information about actual expression levels are available. Additionally, vomeronasal neuroepithelium is already present at early prenatal stages (Garrett et al., 2013) and numerous neurons reactive to Olfactory Marker Proteina marker of terminally differentiated vomeronasal and olfactory neurons-were found in the VNO and MOE sensory epithelium of a 1-day old mouse lemur indicating olfactory functionality at this age (Smith et al., 2007). Infant mouse lemurs open their eyes at the postnatal age of 4-6 days, acoustically communicate with their mothers (Glatston, 1979; Scheumann et al., 2007b), and start to leave the nest by the age of $\sim 21$ days (Lutermann, 2001). Our results imply the potential for the use of olfactory signals between infants and nest mates (including mothers and siblings) or the early perception of predator cues.

In our study one male was almost 12 years old when he died. Wild mouse lemurs suffer from high predation (Scheumann et al., 2007a) and a near-complete population turnover has been reported after 5 years (Kappeler and Rasolarison, 2003; and see Lutermann et al., 2006). In captivity mouse lemurs in a normal photoperiodic regime are considered to be aged beyond the age of 7.5 years (Zimmermann and Radespiel, unpublished results) and can show signs of senescence. Following this definition three of four tested adult individuals were aged. However, aged mouse lemurs did not perform significantly worse than young animals in olfactory discrimination tasks, and only a minority of aged individuals showed altered behavior during an olfactory reversal learning task (Joly et al., 2006). Given the high proportion of expressed genes in all our individuals, we do not predict any decreased functionality of the olfactory organs due to senescence, although deteriorating central nervous processing would be possible in analogy to the hearing system (Schopf et al., 2014). Another explanation for an ongoing importance of the olfactory sense in aged animals could be the need to compensate an agedependent decline of other senses (e.g., vision) with olfaction. However, although age-related visual impairments like cataracts and blindness have been described in captive gray mouse lemurs (Beltran et al., 2007), the individuals in our study were not visually impaired (Dubicanac, personal communication). A study on mice showed evidence of seven age-dependent expression profiles for VRs (Zhang et al., 2010), but testing only one infant and older adults did not allow to detect such profiles in our study. Mouse lemurs were not sacrificed for the purpose of this study and available samples were therefore limited. Animals would have to be euthanized systematically at different ages and in large numbers to collect information about age-dependent expression which cannot be supported for these primates from an ethical point of view. The sporadic availability of samples makes it also difficult to do in situ-hybridization in mouse lemurs on a larger scale.

We only found sex differences in expression in the VNO at a single locus. We assume that a large number of VRs are used to detect predator cues or signature mixtures to identify individuals and these types of information are equally important for both sexes, e.g., to minimize the predation risk or avoid inbreeding. Pheromones used for intraspecific communication should be equally relevant for males and females in most cases. Touhara and Vosshall (2009) assumed that male and female mice have the same set of pheromone receptors and that both sexes might show behavioral differences because of sex-specific neural circuits in the brain. Sex-specific signal transmission has been reported in mice where the same ligand and $V 2 R$ receptor pair induces different behaviors in males and females (Haga et al., 2010; but also Halem et al., 1999). The VNO was also reported to be larger in male rats than in females (Segovia and Guillamón, 1982), but no sex differences in VR expression are known. It has to be mentioned, though, that differences found between the VNO samples in our study could also indicate individual differences. V1Rs show monoallelic expression (Rodriguez et al., 1999; Roppolo et al., 2007) and our reported high number of expressed and most likely functional loci highlights the important role of the vomeronasal system for the sensory ecology of mouse lemurs. The function of each VR, however, is still unclear and has to be analyzed in further studies.

In the present study a large proportion of VRs (59\%) as well as TRPC2 were also expressed in at least one MOE sample. This result was specific to MOE and VNO, since no VR or TRPC2 expression were detected in adjacent maxilloturbinal tissue. TRPC2 is essential for the functionality of the VNO, and is required for signal transduction of both V1Rs and V2Rs (Liman et al., 1999). Male mutant mice lacking TRPC2 did not attack intruding males and indiscriminately mounted males and females (Leypold et al., 2002; Stowers et al., 2002). In our study both the VNO and MOE of mouse lemurs did express TRPC2 indicating functionality of the expressed VR genes in these chemosensory organs. In contrast, whereas in mice expression of TRPC2 in the VNO is similarly strong, only "weak" expression of TRPC2 has been so far reported in the MOE (Liman et al., 1999). The apparently strong expression of TRPC2 in the mouse lemur MOE was therefore unexpected, but in concordance with the expression of a large number of VRs in this organ. However, a quantitative comparison between TRPC2 expression in mice and mouse lemurs is not yet available. Expression of single V1Rs in the MOE was reported in goats, mice and humans (Rodriguez et al., 2000; Wakabayashi et al., 2002; Karunadasa et al., 2006; Ohara et al., 2009; Pascarella et al., 2014). It was also shown in mice that 2heptanone, a pheromone that binds the V1rb2 (Boschat et al., 2002), elicited strong signals in both the main and the accessory olfactory bulb (Xu et al., 2005), the brain structures that receive projections from the MOE or VNO, respectively (see Munger et al., 2009). Here we have found expression of far more VRs in the MOE of mouse lemurs than previously described in any primate, including many loci expressed both in the MOE and VNO. The results were strengthened by the expression of TRPC2 in the MOE. Three main hypotheses may explain the involvement of the MOE in VR-mediated chemosensory pathways: (1) different ligand sensitivities in the two organs, (2) better coordination between the two organs, or (3) different downstream neural pathways of the two organs. 
The first hypothesis incorporates structural differences between MOE and VNO that facilitate the intake of volatile or non-volatile molecules, respectively. This argument is supported by the finding that in mouse lemurs the volatile phase of urine activates the MOE but not the VNO, which is only stimulated by urine in the liquid phase (Schilling et al., 1990). As the VNO lumen is filled with fluid that can be set in motion by vomeronasal pumps in the organ (Meredith et al., 1980; Meredith, 1994), volatile molecules reach the vomeronasal sensory epithelium less easily than non-volatile. Therefore, pheromones or other ligands bound by VRs being more or less volatile might be better perceived by one or the other olfactory organ. However, recent studies reject this classical view as both organs can perceive volatile as well as non-volatile pheromones (reviewed in Zufall and Leinders-Zufall, 2007). Moreover, it would remain unclear, why the same VRs are expressed in both organs.

The other two hypotheses may explain the simultaneous expression: Ohara et al. (2009) suggested that V1Rs expressed in the MOE of goats might first detect pheromones that induce the flehmen response (animal raises the head and curls back the upper lip to facilitate the inflow of molecules to the VNO). According to the authors the pheromones are then quantitatively analyzed with the $V 1 R$ s in the $\mathrm{VNO}$ and levels of airborne pheromones may be too subtle to be detected without the coordination of both olfactory organs.

However, as flehmen is not described in mouse lemurs (but found in ring-tailed lemurs, Bailey, 1978), we present a third hypothesis: the expression of VRs in the MOE may be explained by the use of different neural pathways in both olfactory systems processing the signals in various brain regions (Mestre et al., 1992; Meisami and Bhatnagar, 1998; Meredith, 1998 and see review in Dulac and Wagner, 2006; Touhara and Vosshall, 2009). The MOE projects to the main olfactory bulb that after accessing paleocortical nuclei is connected to higher brain centers (Lledo et al., 2005) allowing adaptive responses based on experience. In contrast, the VNO bypasses cortical structures and projects directly to nuclei of the limbic system which mediates innate responses (Meisami and Bhatnagar, 1998; von Campenhausen and Mori, 2000; Dulac and Wagner, 2006). Given the potential complexity in olfactory signal composition and transmission in a small nocturnal solitary forager such as the mouse lemur and the fundamental structural separation of the two olfactory organs including different neural pathways, it is likely that evolution may have favored some degree of redundancy in the involved cells, receptors and structures to improve sensory abilities. For example, the availability of VR receptors in the MOE would allow mouse lemurs to better process the various olfactory signals that are produced and deposited in several species-specific marking behaviors (e.g., anogenital marking, head rubbing, urine washing, Glatston, 1979; Buesching et al., 1998; Braune et al., 2005).

The expression results showed a higher variation of expressed VRs in the MOE than in the VNO. A potential explanation for this finding could be spatial competition of VR- and olfactory receptor expressing neurons in the MOE. The more than 300 different cells that express olfactory receptors (Matsui et al., 2010) dilute the concentration of VRs making them harder to be detected with our approach. Such spatial limitations could also have favored rather temporal expression of single VRs (possibly based on experience) that could lead to more plasticity in the neuronal circuits. The high variation of expressed VRs in the MOE could also reflect a high variability in the gene regulation of these primates.

Future studies are needed to identify the full genomic repertoire of V1Rs and V2Rs based on the complete genome of mouse lemurs which has been sequenced at $>160 \times$ coverage by Rogers and colleagues at the Baylor College of Medicine Human Genome Sequencing Center and is currently in the assembly and annotation phase (Yoder, personal communication). We hypothesize that the simultaneous expression of a large number of the same VRs in MOE and VNO-which has never been shown in any primate species before-has evolved in mouse lemurs to adequately process a variety of complex olfactory signals, as separate neural pathways of both olfactory systems project to different brain regions performing special functions. Our results indicate a further blurring in the long presumed functional distinction between the VNO and MOE, following on from demonstration of pheromone detection in the MOE of some species, in some cases by olfactory receptors (Hudson and Distel, 1986; Swann et al., 2001; Charra et al., 2012). More emphasis is needed on comparative adaptive function of these VRs in the MOE and VNO of mouse lemurs and other species with large VR repertoires and highly developed olfactory sense.

\section{AUTHOR CONTRIBUTIONS}

The conception and design of the study was done by Philipp Hohenbrink, Nicholas I. Mundy and Ute Radespiel. Material was provided by Elke Zimmermann. The data were acquired by Philipp Hohenbrink and Silke Dempewolf and analyzed by Philipp Hohenbrink. The interpretation of the data was done by Philipp Hohenbrink, Nicholas I. Mundy and Ute Radespiel. The article was drafted by Philipp Hohenbrink and critically revised by all authors. All authors approved the publication of the final version.

\section{ACKNOWLEDGMENTS}

We thank the University of Veterinary Medicine Hannover for supporting the management of the mouse lemur colony and the Institute of Animal Breeding and Genetics for their technical help. We are also grateful to E. B. Keverne for helpful comments on the manuscript. We thank A. D. Yoder for her personal communication about the progress of the mouse lemur genome sequencing and M. Dubicanac for his measurements of the visual capacity of the tested mouse lemurs.

\section{REFERENCES}

Bailey, K. (1978). Flehmen in the ring-tailed lemur (Lemur catta). Behaviour 65, 309-319. doi: 10.1163/156853978X00666

Beltran, W. A., Vanore, M., Ollivet, F., Nemoz-Bertholet, F., Aujard, F., Clerc, B., et al. (2007). Ocular findings in two colonies of gray mouse lemurs (Microcebus murinus). Vet. Ophthalmol. 10, 43-49. doi: 10.1111/j.1463-5224.2007.00491.x

Boschat, C., Pelofi, C., Randin, O., Roppolo, D., Lüscher, C., Broillet, M. C., et al. (2002). Pheromone detection mediated by a V1r vomeronasal receptor. Nat. Neurosci. 5, 1261-1262. doi: 10.1038/nn978

Braune, P., Schmidt, S., and Zimmermann, E. (2005). Spacing and group coordination in a nocturnal primate, the golden brown mouse lemur (Microcebus ravelobensis): the role of olfactory and acoustic signals. Behav. Ecol. Sociobiol. 58, 587-596. doi: 10.1007/s00265-005-0944-4 
Buesching, C. D., Heistermann, M., Hodges, J. K., and Zimmermann, E. (1998). Multimodal oestrus advertisement in a small nocturnal prosimian, Microcebus murinus. Folia Primatol. 69, 295-308. doi: 10.1159/000052718

Chamero, P., Marton, T. F., Logan, D. W., Flanagan, K., Cruz, J. R., Saghatelian, A., et al. (2007). Identification of protein pheromones that promote aggressive behaviour. Nature 450, 899-903. doi: 10.1038/nature05997

Charra, R., Datiche, F., Casthano, A., Gigot, V., Schaal, B., and Coureaud, G. (2012). Brain processing of the mammary pheromone in newborn rabbits. Behav. Brain Res. 226, 179-188. doi: 10.1016/j.bbr.2011.09.008

DelBarco-Trillo, J., Burkert, B. A., Goodwin, T. E., and Drea, C. M. (2011). Night and day: the comparative study of strepsirrhine primates reveals socioecological and phylogenetic patterns in olfactory signals. J. Evol. Biol. 24, 82-98. doi: 10.1111/j.1420-9101.2010.02145.x

Dulac, C., and Axel, R. (1995). A novel family of genes encoding putative pheromone receptors in mammals. Cell 83, 195-206. doi: 10.1016/00928674(95)90161-2

Dulac, C., and Wagner, S. (2006). Genetic analysis of brain circuits underlying pheromone signaling. Annu. Rev. Genet. 40, 449-467. doi: 10.1146/annurev.genet.39.073003.093937

Garrett, E. C., Dennis, J. C., Bhatnagar, K. P., Durham, E. L., Burrows, A. M., Bonar, C. J., et al. (2013). The vomeronasal complex of nocturnal strepsirhines and implications for the ancestral condition in primates. Anat. Rec. 296, 1881-1894. doi: 10.1002/ar22828

Glatston, A. R. H. (1979). Reproduction and Behaviour of the Lesser Mouse Lemur (Microcebus murinus, MILLER 1777) in Captivity. Ph.D. thesis, University of London, University College, London.

Haga, S., Hattori, T., Sato, T., Sato, K., Matsuda, S., Kobayakawa, R., et al. (2010). The male mouse pheromone ESP1 enhances female sexual receptive behaviour through a specific vomeronasal receptor. Nature 466, 118-122. doi: 10.1038/nature09142

Halem, H. A., Cherry, J. A., and Baum, M. J. (1999). Vomeronasal neuroepithelium and forebrain Fos responses to male pheromones in male and female mice. J. Neurobiol. 39, 249-263. doi: 10.1002/(SICI)10974695(199905)39:2<249::AID-NEU9>3.0.CO;2-R

Herrada, G., and Dulac, C. (1997). A novel family of putative pheromone receptors in mammals with a topographically organized and sexually dimorphic distribution. Cell 90, 763-773. doi: 10.1016/S0092-8674(00)80536-X

Hohenbrink, P., Mundy, N. I., Zimmermann, E., and Radespiel, U. (2013). First evidence for functional vomeronasal 2 receptor genes in primates. Biol. Lett. 9, 20121006. doi: 10.1098/rsbl.2012.1006

Hohenbrink, P., Radespiel, U., and Mundy, N. I. (2012). Pervasive and ongoing positive selection in the vomeronasal-1 receptor $(V 1 R)$ repertoire of mouse lemurs. Mol. Biol. Evol. 29, 3807-3816. doi: 10.1093/molbev/mss 188

Hudson, R., and Distel, H. (1986). Pheromonal release of suckling in rabbits does not depend on the vomeronasal organ. Physiol. Behav. 37, 123-128. doi: 10.1016/0031-9384(86)90394-X

Isogai, Y., Si, S., Pont-Lezica, L., Tan, T., Kapoor, V., Murthy, V. N., et al. (2011). Molecular organization of vomeronasal chemoreception. Nature 478, 241-245. doi: $10.1038 /$ nature 10437

Jolly, A. (1966). Lemur Behavior: a Malagasy Field Study, Chicago, IL: University of Chicago Press

Joly, M., Deputte, B., and Verdier, J.-M. (2006). Age effect on olfactory discrimination in a non-human primate, Microcebus murinus. Neurobiol. Aging 27, 1045-1049. doi: 10.1016/j.neurobiolaging.2005.05.001

Kappel, P., Hohenbrink, S., and Radespiel, U. (2011). Experimental evidence for olfactory predator recognition in wild mouse lemurs. Am. J. Primatol. 73, 928-938. doi: 10.1002/ajp.20963

Kappeler, P. M., and Rasolarison, R. M. (2003). "Microcebus, mouse lemurs, tsidy," in The Natural History of Madagascar, eds S. M. Goodman and J. P. Benstead (Chicago; London: The University of Chicago Press), 1310-1315.

Karunadasa, D. K., Chapman, C., and Bicknell, R. J. (2006). Expression of pheromone receptor gene families during olfactory development in the mouse: expression of a V1 receptor in the main olfactory epithelium. Eur. J. Neurosci. 23, 2563-2572. doi: 10.1111/j.1460-9568.2006.04795.x

Keverne, E. B. (1999). The vomeronasal organ. Science 286, 716-720. doi: $10.1126 /$ science. 286.5440 .716

Kimoto, H., Haga, S., Sato, K., and Touhara, K. (2005). Sex-specific peptides from exocrine glands stimulate mouse vomeronasal sensory neurons. Nature 437, 898-901. doi: 10.1038/nature04033
Leinders-Zufall, T., Brennan, P., Widmayer, P., Chandramani, P., Maul-Pavicic, A., Jager, M., et al. (2004). MHC class I peptides as chemosensory signals in the vomeronasal organ. Science 306, 1033-1037. doi: 10.1126/science. 1102818

Leinders-Zufall, T., Lane, A. P., Puche, A. C., Ma, W. D., Novotny, M. V., Shipley, M. T., et al. (2000). Ultrasensitive pheromone detection by mammalian vomeronasal neurons. Nature 405, 792-796. doi: 10.1038/35015572

Leypold, B. G., Yu, C. R., Leinders-Zufall, T., Kim, M. M., Zufall, F., and Axel, R. (2002). Altered sexual and social behaviors in trp2 mutant mice. Proc. Natl. Acad. Sci. U.S.A. 99, 6376-6381. doi: 10.1073/pnas.082127599

Liman, E. R., Corey, D. P., and Dulac, C. (1999). TRP2: a candidate transduction channel for mammalian pheromone sensory signaling. Proc. Natl. Acad. Sci. U.S.A. 96, 5791-5796. doi: 10.1073/pnas.96.10.5791

Liman, E. R., and Innan, H. (2003). Relaxed selective pressure on an essential component of pheromone transduction in primate evolution. Proc. Natl. Acad. Sci. U.S.A. 100, 3328-3332. doi: 10.1073/pnas.0636123100

Lledo, P. M., Gheusi, G., and Vincent, J. D. (2005). Information processing in the mammalian olfactory system. Physiol. Rev. 85, 281-317. doi: 10.1152/physrev.00008.2004

Lutermann, H. (2001). Weibchenassoziationen und Fortpflanzungsstrategien Beim Grauen Mausmaki (Microcebus murinus) in Nordwest-Madagaskar. Ph.D. thesis, University of Hannover, Hannover, Germany.

Lutermann, H., Schmelting, B., Radespiel, U., Ehresmann, P., and Zimmermann, E. (2006). The role of survival for the evolution of female philopatry in a solitary forager, the grey mouse lemur (Microcebus murinus). Proc. R. Soc. B. 273, 2527-2533. doi: 10.1098/rspb.2006.3603

Martin, R. D. (1990). Primate Origins and Evolution: a Phylogenetic Reconstruction. London: Chapman and Hall.

Matsui, A., Go, Y., and Niimura, Y. (2010). Degeneration of olfactory receptor gene repertories in primates: no direct link to full trichromatic vision. Mol. Biol. Evol. 27, 1192-1200. doi: 10.1093/molbev/msq003

Matsunami, H., and Buck, L. B. (1997). A multigene family encoding a diverse array of putative pheromone receptors in mammals. Cell 90, 775-784. doi: 10.1016/S0092-8674(00)80537-1

Meisami, E., and Bhatnagar, K. P. (1998). Structure and diversity in mammalian accessory olfactory bulb. Microsc. Res. Tech. 43, 476-499. doi: 10.1002/(SICI)1097-0029(19981215)43:6<476::AID-JEMT2>3.0.CO;2-V

Meredith, M. (1994). Chronic recording of vomeronasal pump activation in awake behaving hamsters. Physiol. Behav. 56, 345-354. doi: 10.1016/00319384(94)90205-4

Meredith, M. (1998). Vomeronasal, olfactory, hormonal convergence in the brain. cooperation or coincidence? Ann. N.Y. Acad. Sci. 855, 349-361. doi: 10.1111/j.1749-6632.1998.tb10593.x

Meredith, M., Marques, D. M., O’Connell, R. O., and Stern, F. L. (1980). Vomeronasal pump: significance for male hamster sexual behavior. Science 207, 1224-1226. doi: 10.1126/science.7355286

Mestre, N., Petter, A., and Bons, N. (1992). Systematisation of the olfactory bulb efferent projections in a lemurian primate: Microcebus murinus. J. Hirnforsch. 33, 173-184

Munger, S. D., Leinders-Zufall, T., and Zufall, F. (2009). Subsystem organization of the mammalian sense of smell. Annu. Rev. Physiol. 71, 115-140. doi: 10.1146/annurev.physiol.70.113006.100608

Ohara, H., Nikaido, M., Date-Ito, A., Mogi, K., Okamura, H., Okada, N., et al. (2009). Conserved repertoire of orthologous vomeronasal type 1 receptor genes in ruminant species. BMC Evol. Biol. 9:233. doi: 10.1186/1471-2148-9-233

Pascarella, G., Lazarevic, D., Plessy, C., Bertin, N., Akalin, A., Vlachouli, C., et al. (2014). NanoCAGE analysis of the mouse olfactory epithelium identifies the expression of vomeronasal receptors and of proximal LINE elements. Front. Cell. Neurosci. 8:41. doi: 10.3389/fncel.2014.00041

Perret, M. (1995). "Chemocommunication in the reproductive function of mouse lemurs," in Creatures of the Dark: the Nocturnal Prosimians, eds L. Alterman, G. A. Doyle, and K. M. Izard (New York, NY: Plenum Press), 377-392.

Radespiel, U., and Zimmermann, E. (2001). Female dominance in captive gray mouse lemurs (Microcebus murinus). Am. J. Primatol. 54, 181-192. doi: 10.1002/ajp.1029

Restrepo, D., Arellano, J., Oliva, A. M., Schaefer, M. L., and Lin, W. H. (2004). Emerging views on the distinct but related roles of the main and accessory olfactory systems in responsiveness to chemosensory signals in mice. Horm. Behav. 46, 247-256. doi: 10.1016/j.yhbeh.2004.02.009 
Rodriguez, I., Feinstein, P., and Mombaerts, P. (1999). Variable patterns of axonal projections of sensory neurons in the mouse vomeronasal system. Cell 97, 199-208. doi: 10.1016/S0092-8674(00)80730-8

Rodriguez, I., Greer, C. A., Mok, M. Y., and Mombaerts, P. (2000). A putative pheromone receptor gene expressed in human olfactory mucosa. Nat. Genet. 26, 18-19. doi: 10.1038/79124

Roppolo, D., Vollery, S., Kan, C.-D., Lüscher, C., Broillet, M.-C., and Rodriguez, I. (2007). Gene cluster lock after pheromone receptor gene choice. EMBO J. 26, 3423-3430. doi: 10.1038/sj.emboj.7601782

Ryba, N. J., and Tirindelli, R. (1997). A new multigene family of putative pheromone receptors. Neuron 19, 371-379. doi: 10.1016/S0896-6273(00) 80946-0

Scheumann, M., Rabesandratana, A., and Zimmermann, E. (2007a). "Predation, communication, and cognition in lemurs," in Primate Anti-Predator Strategies, eds S. L. Gursky and K. A. I. Nekaris (New York, NY: Springer), 100-123. doi: 10.1007/978-0-387-34810-0_5

Scheumann, M., Zimmermann, E., and Deichsel, G. (2007b). Context-specific calls signal infant's need in a strepsirrhine primate, the gray mouse lemur (Microcebus murinus). Dev. Psychobiol. 49, 708-718. doi: 10.1002/dev.20234

Schilling, A., Serviere, J., Gendrot, G., and Perret, M. (1990). Vomeronasal activation by urine in the primate Microcebus murinus: a 2 DG study. Exp. Brain Res. 81, 609-618. doi: 10.1007/BF02423511

Schopf, C., Zimmermann, E., Tünsmeyer, J., Kästner, S. B. R., Hubka, P., and Kral, A. (2014). Hearing and age-related changes in the gray mouse lemur. J. Assoc. Res. Otolaryngol. doi: 10.1007/s10162-014-0478-4. [Epub ahead of print].

Segovia, S., and Guillamón, A. (1982). Effects of sex steroids on the development of the vomeronasal organ in the rat. Dev. Brain Res. 5, 209-212. doi: 10.1016/01653806(82)90160-2

Smith, T. D., Alport, L. J., Burrows, A. M., Bhatnagar, K. P., Dennis, J. C., Tuladhar, P., et al. (2007). Perinatal size and maturation of the olfactory and vomeronasal neuroepithelia in lorisoids and lemuroids. Am. J. Primatol. 69, 74-85. doi: 10.1002/ajp.20328

Smith, T. D., Garrett, E. C., Bhatnagar, K. P., Bonar, C. J., Bruening, A. E., Dennis, J. C., et al. (2011). The vomeronasal organ of New World monkeys (Platyrrhini). Anat. Rec. 294, 2158-2178. doi: 10.1002/ar.21509

Smith, T. D., and Rossie, J. B. (2008). Nasal fossa of mouse and dwarf lemurs (primates, cheirogaleidae). Anat. Rec. 291, 895-915. doi: 10.1002/ar.20724

Stowers, L., Holy, T. E., Meister, M., Dulac, C., and Koentges, G. (2002). Loss of sex discrimination and male-male aggression in mice deficient for TRP2. Science 295, 1493-1500. doi: 10.1126/science.1069259

Sündermann, D., Scheumann, M., and Zimmermann, E. (2008). Olfactory predator recognition in predator-naive gray mouse lemurs (Microcebus murinus). J. Comp. Psychol. 122, 146-155. doi: 10.1037/0735-7036.122.2.146

Swann, J., Rahaman, F., Bijak, T., and Fiber, J. (2001). The main olfactory system mediated pheromone-induced fos expression in the extended amygdala and preoptic area of the male Syrian hamster. Neurosci 105, 695-706. doi: 10.1016/S0306-4522(01)00227-5

Talarico, M. F. (2006). Molecular Evolution of Olfactory and Vomeronasal Receptor Genes and Olfactory Communication in Primates. Dept. Zoology. M.Sc. thesis, University of Cambridge, Cambridge.

Tamura, K., Peterson, D., Peterson, N., Stecher, G., Nei, M., and Kumar, S. (2011). MEGA5: molecular evolutionary genetics analysis using maximum likelihood, evolutionary distance, and maximum parsimony methods. Mol. Biol. Evol. 28, 2731-2739. doi: 10.1093/molbev/msr121

Touhara, K., and Vosshall, L. B. (2009). Sensing odorants and pheromones with chemosensory receptors. Annu. Rev. Physiol. 71, 307-332. doi: 10.1146/annurev.physiol.010908.163209
Untergasser, A., Nijveen, H., Rao, X., Bisseling, T., Geurts, R., and Leunissen, J. A. M. (2007). Primer3Plus, an enhanced web interface to Primer3. Nucleic Acids Res. 35, W71-W74. doi: 10.1093/nar/gkm306

von Campenhausen, H., and Mori, K. (2000). Convergence of segregated pheromonal pathways from the accessory olfactory bulb to the cortex in the mouse. Eur. J. Neurosci. 12, 33-46. doi: 10.1046/j.1460-9568.2000.00879.x

Wakabayashi, Y., Mori, Y., Ichikawa, M., Yazaki, K., and Hagino-Yamagishi, K. (2002). A putative pheromone receptor gene is expressed in two distinct olfactory organs in goats. Chem. Senses 27, 207-213. doi: 10.1093/chemse/ 27.3.207

Wrogemann, D., Radespiel, U., and Zimmermann, E. (2001). Comparison of reproductive characteristics and changes in body weight between captive populations of rufous and gray mouse lemurs. Int. J. Primatol. 22, 91-108. doi: 10.1023/A:1026418132281

Wrogemann, D., and Zimmermann, E. (2001). Aspects of reproduction in the Eastern rufous mouse lemur (Microcebus rufus) and their implications for captive management. Zoo Biol. 20, 157-167. doi: 10.1002/zoo.1017

Xu, F., Schaefer, M., Kida, I., Schafer, J., Liu, N., Rothman, D. L., et al. (2005). Simultaneous activation of the mouse main and accessory olfactory bulb by odors or pheromones. J. Comp. Neurol. 489, 491-500. doi: 10.1002/cne. 20652

Yoder, A. D., Chan, L. M., Dos Reis, M., Larsen, P. A., Campbell, C. R., Rasolarison, R., et al. (2014). Molecular evolutionary characterization of a V1R subfamily unique to strepsirrhine primates. Genome Biol. Evol. 6, 213-227. doi: 10.1093/gbe/evu006

Young, J. M., Massa, H. F., Hsu, L., and Trask, B. J. (2010). Extreme variability among mammalian V1R gene families. Genome Res. 20, 10-18. doi: 10.1101/gr.098913.109

Young, J. M., and Trask, B. J. (2007). V2R gene families degenerated in primates, dog and cow, but expanded in opossum. Trends Genet. 23, 212-215. doi: 10.1016/j.tig.2007.03.004

Zhang, J. Z., and Webb, D. M. (2003). Evolutionary deterioration of the vomeronasal pheromone transduction pathway in catarrhine primates. Proc. Natl. Acad. Sci. U.S.A. 100, 8337-8341. doi: 10.1073/pnas.1331721100

Zhang, X., Marcucci, F., and Firestein, S. (2010). High-throughput microarray detection of vomeronasal receptor gene expression in rodents. Front. Neurosci. 4:164. doi: 10.3389/fnins.2010.00164

Zufall, F., and Leinders-Zufall, T. (2007). Mammalian pheromone sensing. Curr. Opin. Neurobiol. 17, 483-489. doi: 10.1016/j.conb.2007.07.012

Conflict of Interest Statement: The authors declare that the research was conducted in the absence of any commercial or financial relationships that could be construed as a potential conflict of interest.

Received: 14 July 2014; accepted: 05 September 2014; published online: 24 September 2014.

Citation: Hohenbrink P, Dempewolf S, Zimmermann E, Mundy NI and Radespiel $U$ (2014) Functional promiscuity in a mammalian chemosensory system: extensive expression of vomeronasal receptors in the main olfactory epithelium of mouse lemurs. Front. Neuroanat. 8:102. doi: 10.3389/fnana.2014.00102

This article was submitted to the journal Frontiers in Neuroanatomy.

Copyright (c) 2014 Hohenbrink, Dempewolf, Zimmermann, Mundy and Radespiel. This is an open-access article distributed under the terms of the Creative Commons Attribution License (CC BY). The use, distribution or reproduction in other forums is permitted, provided the original author(s) or licensor are credited and that the original publication in this journal is cited, in accordance with accepted academic practice. No use, distribution or reproduction is permitted which does not comply with these terms. 